21. Craxton, M. Genomic analysis of synaptotagmin genes. Genomics 77, 43-49 (2001).

22. Mackler, J. M. \& Reist, N. E. Mutations in the second C2 domain of synaptotagmin disrupt synaptic transmission at Drosophila neuromuscular junctions. J. Comp. Neurol. 436, 4-16 (2001).

23. Chapman, E. R., Desai, R. C., Davis, A. F. \& Tornehl, C. K. Delineation of the oligomerization, AP-2 binding, and synprint binding region of the C2B domain of synaptotagmin. J. Biol. Chem. 273, 32966-32972 (1998)

24. Rickman, C. et al. Synaptotagmin interaction with the syntaxin/SNAP-25 dimer is mediated by an evolutionarily conserved motif and is sensitive to inositol hexakisphosphate. J. Biol. Chem. 279, 12574-12579 (2004)

25. Grass, I., Thiel, S., Honing, S. \& Haucke, V. Recognition of a basic AP-2 binding motif within the C2B domain of synaptotagmin is dependent on multimerization. J. Biol. Chem. 279, 54872-54880 (2004).

26. Nakhost, A., Houeland, G., Blandford, V. E., Castellucci, V. F. \& Sossin, W. S. Identification and characterization of a novel C2B splice variant of synaptotagmin I. J. Neurochem. 89, 354-363 (2004).

27. Reenan, R., Hanrahan, C. \& Ganetzky, B. The mle(napts) RNA helicase mutation in Drosophila results in a splicing catastrophe of the para $\mathrm{Na}^{+}$channel transcript in a region of RNA editing. Neuron 25 , 139-149 (2000).

28. Aruscavage, P. \& Bass, B. A phylogenetic analysis reveals an unusual sequence conservation within introns involved in RNA editing. RNA 6, 257-269 (2000).
29. Kung, S. S., Chen, Y. C., Lin, W. H., Chen, C. C. \& Chow, W. Y. Q/R RNA editing of the AMPA receptor subunit 2 (GRIA2) transcript evolves no later than the appearance of cartilaginous fishes. FEBS Lett. 509, 277-281 (2001).

30. Wheeler, W. C., Whiting, M., Wheeler, Q. D. \& Carpernter, J. M. The phylogeny of the extant hexapod orders. Cladistics 17, 113-169 (2001).

\section{Supplementary Information accompanies the paper on www.nature.com/nature.}

Acknowledgements I thank L. Reenan for discussions; B. Hoopengardner, T. Bhalla and A. Das for comments on the manuscript; B. Hoopengardner for sharing certain genomic DNA templates and for assistance with S2 cell culture; UCHC Molecular Core Facility staff for diligent sequencing efforts; and M. Lalande for his encouragement. This work was supported by grants from the

National Science Foundation and National Institutes of Health (R.A.R.).

Competing interests statement The author declares that he has no competing financial interests.

Correspondence and requests for materials should be addressed to R.A.R.

(rreenan@neuron.uchc.edu).

erratum

\title{
Pleistocene to Holocene extinction dynamics in giant deer and woolly mammoth
}

\section{A. J. Stuart, P. A. Kosintsev, T. F. G. Higham \& A. M. Lister}

Nature 431, 684-689 (2004).

In Fig. 4 of this Letter, some of the data were not properly aligned with their location labels. The corrected figure is shown here.

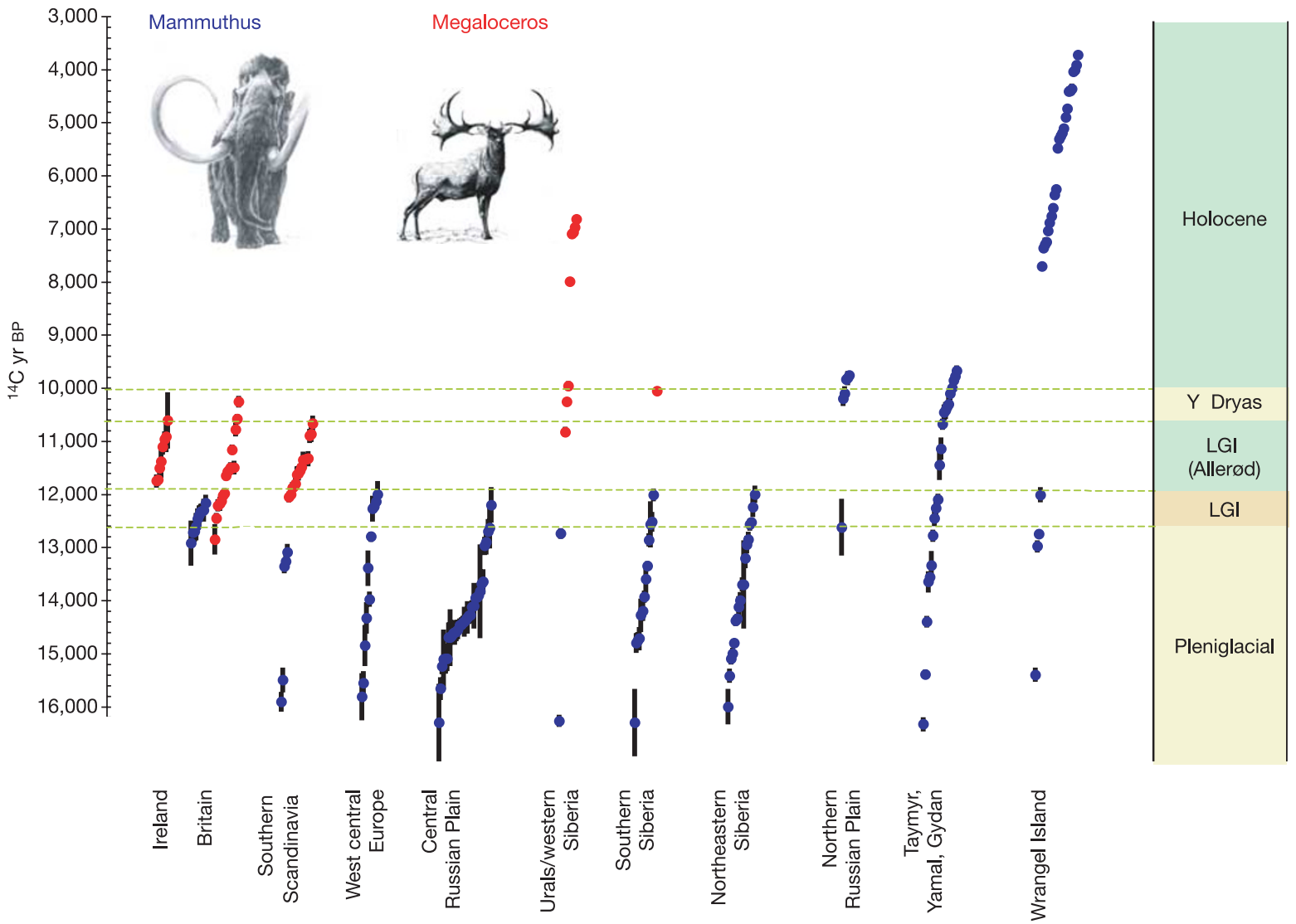

